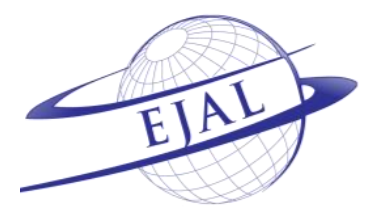

Available online at www.ejal.eu

\title{
Review of Linguistic Pragmatics of Intercultural Professional and Business Communication
}

\author{
Cüneyt Demir a * (D) \\ a Siirt University, Kezer Campus, Siirt, 56100, Turkey
}

Received 27 November 2018 | Received in revised form 24 January 2019 | Accepted 10 February 2019

\begin{abstract}
APA Citation:
Demir, C. (2019). Review of linguistic pragmatics of intercultural professional and business communication. Eurasian Journal of Applied Linguistics, 5(3), 537-541. Doi: 10.32601/ejal.651350
\end{abstract}

\begin{abstract}
Linguistic Pragmatics of Intercultural Professional and Business Communication, Elena N. Malyuga and Svetlana N. Orlova. Springer, Cham / Switzerland (2018). 145 pp., Hardcover: \$109.99, ISBN:978-3-319-68743-8, eBook: \$84.99, ISBN:978-3-319-68744-5

(C) 2019 EJAL \& the Authors. Published by Eurasian Journal of Applied Linguistics (EJAL). This is an open-access article distributed under the terms and conditions of the Creative Commons Attribution license (CC BY-NC-ND) (http://creativecommons.org/licenses/by-nc-nd/4.0/).
\end{abstract}

Keywords: linguistic pragmatics; intercultural; professional; business; communication

Linguistic Pragmatics of Intercultural Professional and Business Communication (2018) is a book offering valuable insights on business communication through investigating inherent norms and rules of effective communication under the framework of linguistic and extralinguistic features. The book has two authors, both of whom work at different universities in Russia, and have specific studies on discourse analysis, pragmatics and sociolinguistics. The authors completely support that national and cultural identity of a speaker evidently affects the efficiency of business communication; therefore, a professional business interaction can be achieved through the knowledge of the culture, from which a language cannot be separated. Accordingly, the rationale behind this work is to elicit a link between successful business communication and cultural awareness of the spoken language. Furthermore, the primary aim of the book is to draw attention on the importance of Intercultural Professional and Business Communication (IPBC) which is considered a complex process that should not be taken for granted. Handbook of Business Communication (Mautner \& Rainer, 2017) seems to be the nearest resource to this book, though it is a much more extensive compilation together with its additions of lexical phenomena and practical implementations on language and communication problems.

The book is divided into four chapters; each of which covers a specific topic, a summary, and a reference list. Chapter one develops a link between contemporary business communication and IPBC while the chapter two concentrates on proving the importance of professional discourse on particularly lexical base together with

\footnotetext{
* Corresponding author Tel.: +90-505-937-4345

E-mail address: cuneytdemir@siirt.edu.tr
} 
phonetical and grammatical units. Different from the first two chapters which are based on theoretical perspectives, the third chapter defines one of the discursive features gaining ascendance in the recent past: Euphemism. Whilst the third chapter is all about euphemism in different contexts, the last chapter focuses on the role of euphemism distinctively in IPBC. In brief, the chapters fall largely into two categories: communication and discourse. The first two chapters explore discourse and business jargonisms while the last two chapters entirely mention the discursive device of euphemism.

With five sub-titles, the first chapter mainly defines the term professional language which establishes the base of the book. The authors define professional language not only as a communication system including accurate use of linguistic features, but also a system composed of cultural, social, and even extralinguistical knowledge. Having laid the foundation of basic theoretical perspectives of professional language, the authors tell a short story of linguistic globalisation and its diffusion in the Europe, and then linguacultural and lingua-pragmatic features of IPBC are uttered through authentic samples from media and ready-made metaphors borrowed from other languages (French and Italian). The chapter ends with providing lexical characteristics of IPBC. The chapter is beneficial for providing background knowledge for readers on basic theoretical perspectives of discourse in a language. Through bottom-up process, the authors aimed at reaching business discourse from general discourse in linguistics; however, some redundant information disrupts the integrity of the issue (e.g. second subtitle, Linguistic Globalisation and Internationalisation and Their Diffusion in the European, does not seem much enlightening). It might have been better for readers if the authors had included a subtitle referring to what makes business communication different from other specific communication types, or a subtitle dedicated to the controversial issue of whether business communication could further be divided into sub-categories (c.f. Thill \& Bovee, 2014).

Chapter 2, the longest chapter, focuses on issues relating to jargons used in business discourse. According to the authors, lexical-phraseological structures in texts determine the stylistic features of discourse since professional language does not have a grammatical system of its own. The chapter includes some analyses of communicative strategies to detect speakers' language manipulation (speech behaviour of speaker to perceive the interlocutor); accordingly, it is mentioned that strategy of manipulation is highly affected by factors such as specific characteristics of natural-cultural scenarios, communicative situation, and social status of the participants. The chapter is useful in forming a base which develops theoretical background regarding lexical-phraseological structures of communicative strategies in business. On the other hand, it necessitates for readers to have proficient background knowledge in order to understand the chapter because it is too elaborately written. The primary purpose of writing is to convey information to others, which is why plain writing has been gaining ascendance in the writing world. Therefore, a welcome addition would be with regard to the complicated language that was used in this book. Many jargons and specific terms may prevent flow in reading particularly if your 
audiences are not specialized over the issue. It seems that the book aims at addressing a wide scope of audience rather than a small linguistic community, which could be achieved only through a plain language.

Chapter 3 starts with a comprehensive definition of euphemism, and then follows the use of it in different discourses such as politics, language, economy, and headlines where accurate expression is of utmost importance. Having classified them, the authors conclude that euphemism is a speech act based on lexical phenomenon; however, it is possible to construct euphemistic expressions on phrasal/sentential bases (c.f. Burkhardt, 2010). The major imperfection of this part of the book is its sheer long-windedness on fields other than business. The chapter provides too much literature review on euphemism, which could be placed in the first chapter briefly or the chapter could already be merged with the last chapter.

The last chapter comprehensively focuses on the use of euphemism in IPBC. How to use euphemistic expressions effectively in professional business communication is expressed in a detailed way. The chapter also provides information on factors affecting the use of euphemism in IPBC. Of many reasons regarding the use of euphemism, the authors conclude that there are two main reasons to use euphemism in IPBC: a need for manipulating the speech through psychological interferences and the desire to avoid communicative conflicts through mitigating the speech. A warm welcome to this chapter would be the issue of gender in using euphemistic devices because studies conducted in myriad fields regarding the importance of gender on euphemism (as well as dysphemism) can be found readily in the relevant literature. Although it is an old study, Kenton's (1989) specific study that combined the issues of business communication, gender, and euphemism is a good example. One thing concerning this chapter would be lack of cultural effect on euphemism because the speakers' culture affects the way they talk and the discourse markers they use in their conversations; there are studies arguing the interpretation of euphemism in cross culture communication (see Xin, 2015). It seems that the book downgraded or missed the importance of euphemism in cross culture communications although it has a tittle referring to this issue.

Taken together, the strong point of this book is that it offers a comprehensive review of euphemism not only in business discourse, but also in other related discourses. On the whole, the book raises our awareness of the possible relation between culture, business, and discourse, which has not been regarded much relevant so far. The book successfully creates an impression on the reader in that those who want to have a professional communication skill should not overlook the importance of culture and the discourse device of euphemism. However, there is still some room for minor critical remarks; for example, the book studies euphemistic expressions in business communication by investigating three languages, namely English, French and Italian, though there is a parsimonious account of why these languages had been selected. Metaphorical and regular euphemistic expressions across these languages could be compared in a more systematic way under specific subtitles. Another point that the book falls short is that it focuses on theoretical framework more than 
necessary. The book is like a literature review of gathering business discourse and euphemism. Empirical data does not seem sufficient to conclude a spot-on result. Therefore, it might be better if the book had included more authentic comparative samples from the three languages investigated in the book.

The book may be beneficial for individual entrepreneurs aiming at using a language efficiently in professional business communication thanks to its authentic examples that could be used in real-life situations. While many books fall short in constructing a bridge between theoretical information and practical implementations, this book accomplishedly merge theoretical information provided in the first two chapters and practical implementations in the latter chapters. One of the flairs truly needed in the workplace is to be able to have practical oral communication (Glenda \& Ian, 2002), which the book tries to touch upon though authentic workplace samples. Inside a continuum of business English books, this book is beneficial with its combination of culture, discursive features of language, and business. Furthermore, the book can be detached from the similar books (e.g. Chaney \& Martin, 2013; Gibson, 2002) in the literature in that it emphasizes the importance of using a mitigated language through euphemism in business communication of different cultures, and focuses on improving communication skill in business English rather than general business communication skills.

These minor caveats should not detract from the positive contribution that this book makes to the discourse studies. Despite my reservations, the book has many merits. Linguistic Pragmatics of Intercultural Professional and Business Communication is a valuable book for instructors who would like to have a course book of ESP business communication because it orderly submits theoretical information that may be used as ready-made source by them. Furthermore, the book may help those who aim to improve self-professional communication skill in business world, though it is going to enlighten readers only about why and how to use euphemistic expressions in business communication.

\section{References}

Burkhardt, A. (2010). Euphemism andTruth. In A. Burkhardt, \& B. Nerlich, Burkhardt, A. (2010). Euphemism and truth. Tropical truth (s): The epistemology of metaphor and other tropes (pp. 355-372). Berlin / New York: De Gruyter.

Chaney, L., \& Martin, J. (2013). Intercultural Business Communication. Pearson.

Gibson, R. (2002). Intercultural Business Communication: An introduction to the theory and practice of intercultural business communication. Oxford: Oxford Press.

Glenda, C., \& Ian, W. (2002). Oral communication: the workplace needs and uses of business graduate employees. English for Specific Purposes, (21), 41-57.

Kenton, S. B. (1989). Speaker Credibility in Persuasive Business Communication: A Model Which Explains Gender Differences. International Journal of Business Communication, 26(2), 143-157.

Mautner, G., \& Rainer, F. (2017). Handbook of Business Communication. Berlin: De Gruyter.

Thill, J. V., \& Bovee, C. L. (2014). Excellence in Business Communication. Pearson. 
Xin, W. (2015). Cooperative Principle in English Euphemism. English Language Teaching, (3) $1,11-14$.

\section{Copyrights}

Copyright for this article is retained by the author(s), with first publication rights granted to the Journal. This is an open-access article distributed under the terms and conditions of the Creative Commons Attribution license (CC BY-NC-ND) (http://creativecommons.org/licenses/by-nc-nd/4.0/). 